\title{
In Sickness and in Health? Physical IIIness as a Risk Factor for Marital Dissolution in Later Life
}

\author{
Amelia Karraker ${ }^{1,{ }^{*}}$ and Kenzie Latham ${ }^{2}$ \\ ${ }^{1}$ Department of Human Development and Family Studies, lowa State University \\ ${ }^{2}$ Department of Sociology, Indiana University-Purdue University Indianapolis
}

\begin{abstract}
The health consequences of marital dissolution are well-known, but little work has examined the impact of health on the risk of marital dissolution. In this study we use a sample of 2,701 marriages from the Health and Retirement Study (HRS; 1992-2010) to examine the role of serious physical illness onset (i.e., cancer, heart problems, lung disease, and/or stroke) in subsequent marital dissolution due to either divorce or widowhood. We use a series of discrete-time event history models with competing risks to estimate the impact of husband's and wife's physical illness onset on risk of divorce and widowhood. We find that only wife's illness onset is associated with elevated risk of divorce, while either husband's or wife's illness onset is associated with elevated risk of widowhood. These findings suggest the importance of health as a determinant of marital dissolution in later life via both biological and gendered social pathways.
\end{abstract}

A large body of literature has identified marital status as a strong predictor of health and well-being. Not only are the married healthier than the unmarried (e.g., Lillard and Waite 1995; Umberson 1992), but studies also find that both divorce and widowhood are precursors to declines in physical and mental health (e.g., Hughes and Waite 2009; Williams and Umberson 2004). Less attention, however, has been paid to how health may be a determinant of marital status. Work in this area has tended to focus on the positive selection of the healthier into marriage (e.g., Byrne et al. 1989; Smith and Smith 2010), but poor health may be an equally important force for selection out of marriage. Biological processes associated with poor health and illness increase mortality risk (Murphy, Xu, and Kochanek 2013), and thus elevate the risk of marital dissolution via widowhood. However, physical illness may also increase divorce risk via social processes by operating as a stressor on the marital relationship, leading to lower marital quality (Daniel, Wolfe, Busch, and McKevitt 2009; Yorgason, Booth, and Johnson 2008; Amato 2010). Illness may initiate changes to spouses' roles - in particular, increasing caregiving responsibilities for the healthy spouse which can tax marital relationship dynamics (Wolff and Kasper 2006). Illness may also decrease household income due to the inability of one or both spouses to work (Teachman 2010), which may also increase marital strain.

*Address correspondence to Amelia Karraker, Department of Human Development and Family Studies, Iowa State University. 1331 Palmer, Ames, IA, 50011, karraker@iastate.edu. 
Only a few studies have examined the role of poor health in subsequent divorce, and these studies are mixed in their findings, with some finding poor health positively associated with elevated divorce risk (Joung, van de Mheen, Stronks, van Poppel, and Mackenbach 1998; Teachman 2010; Wilson and Waddoups 2002), while others finding no association (Charles and Stephens 2004). These studies also tend to examine relatively young samples, although the implications of poor health for divorce may be particularly important as individuals age. Chronic morbidity incidence increases with age (Crimmins and Beltrán-Sánchez 2011), while decreasing mortality associated with several chronic diseases (Crimmins 2004) means that individuals are living longer with chronic illnesses and marriages are at decreased risk of dissolution due to widowhood than in the past. One consequence of this increased likelihood of longer term survival with chronic illness may be increased divorce risk.

The relationship between spousal health and divorce may also vary by gender. Small clinical studies have found a larger risk of divorce when wives become ill than when husbands do (e.g., Glantz et al. 2009) or, in particular, when wives as opposed to husbands are diagnosed with cancer (Carlsen et al. 2007). This variation by gender is consistent with the increasing advantage enjoyed by men in (re)marriage markets over the life course due to an everexpanding pool of potential partners, and with findings that husbands may find caring for an ill spouse more stressful than do wives (England 2005). While the few clinical studies finding gender differences in the impact of illness on divorce risk are intriguing, these results have not been replicated in large social surveys or across an array of illnesses.

We use a sample of marriages from the initial cohort of the nationally representative Health and Retirement Study (HRS; 1992-2010) to examine the relationship between serious physical illness onset (i.e., cancer, heart problems, lung disease, and/or stroke) among marriages in which at least one spouse is middle-aged at baseline and subsequent marital dissolution due to either divorce or widowhood. We also look at whether the relationship between illness and marriage dissolution varies by specific illness or, in the case of divorce, by gender. Estimating competing risk models for divorce and widowhood (compared with remaining married) for this sample contributes to research addressing trends in the relative contributions of divorce and widowhood to marriage dissolution at older ages (Stevenson and Wolfers 2007). Examining several types of physical illnesses/conditions enables a consideration of how the risk of divorce may be impacted by the associated characteristics of each illness/condition, such as level of disability, chronicity, and social meaning. Finally, analyzing the risk of divorce by whether it is the husband or wife who experiences illness onset furthers understanding of gendered experiences at the intersections of health and marriage in later life.

\section{Background}

\section{Health as a Determinant of Marital Status}

The relationship between marital status and health is well-known. Numerous studies have documented the health benefits to getting married (Lillard and Waite 1995; Umberson 1992). Studies also find negative health consequences of marital dissolution due to either divorce (Hughes and Waite 2009; Williams and Umberson 2004) or widowhood (Hughes and Waite 2009). The vast majority of this literature, however, has focused on the impact of marital 
status and transitions on health, rather than on the impact of health on subsequent marital status.

Much of the literature focusing on health as a determinant of marital status has focused on positive selection of the healthy into marriage (e.g. Byrne et al. 1989; Fikkan and Rothblum 2012; Gortmaker et al. 1993; Smith and Smith 2010). Some other studies also suggest that health not only functions as a determinant of entry into marriage but also of marital dissolution. Beyond the obvious pathway between a partner's health decline and subsequent widowhood, a few studies have examined physical health as a risk factor for marital dissolution via divorce. A meta-analysis of social and economic consequences of stroke among working age adults also found some evidence of an elevated divorce risk following stroke, as well as increased marital conflict and decreased sexual activity (Daniel, Wolfe, Busch, and McKevitt 2009), which may be precursors for divorce. Other studies have found that the relationship between illness and divorce may vary by specific illness. To illustrate, a Norwegian study did not find strong evidence for elevated divorced following cancer diagnosis, except for cervical and testicular cancers, which tend to strike younger individuals than many other cancers (Syse and Kravdal 2007). However, some studies find no evidence that poor health is a risk factor for divorce. For example, in their examination of marriages among mostly working-aged individuals, Charles and Stephens (2004) did not find disability related to subsequent divorce.

While the extant literature does not demonstrate a clear association between illness onset and risk of divorce, there are several reasons why we may expect that illness onset is linked to subsequent divorce. First, a sick individual may require assistance with daily personal care tasks, and for those who are married, the ill individual's spouse is most often the primary caregiver (Wolff and Kasper 2006). Caregiving has been identified as a source of psychological strain which may lead to increased morbidity and mortality among caregivers themselves (Schulz and Beach 1999). Second, caregiving may alter the relationship dynamics between husband and wife in ways that are distressing, particularly if initial marital quality was low (Choi and Marks 2006). In addition, one spouse's illness may affect household income by interfering with either the ill or caregiving spouse's ability to engage in gainful employment. While both job loss and earnings shocks have been linked to elevated divorce risk (Charles and Stephens 2004; Weiss and Willis 1997), Singleton (2012) demonstrated that the impact of work-preventing disability onset on divorce was greatest among younger and better educated men, which suggests that lost potential earnings may not be as meaningful for older couples.

A limitation of most of the studies that examine health and divorce is a focus on relatively young populations. Recent evidence suggests, however, that divorce at older ages is on the rise. The number of divorces occurring among adults aged 50 and older has doubled in the past two decades, and in 2010 one in four divorces occurred among those over 50 (Brown and Lin 2012). Late middle-age and early older-ages are the stage in the life course when many individuals experience the onset of serious health conditions, and given more permissive attitudes towards divorce and the more frequent experience of divorce earlier in life (Uhlenberg and Myers 1981), illness onset may be an increasingly important risk factor for divorce among more recent cohorts of older Americans. 
One prior study of marriages in which at least one spouse was in late-middle or early-old age found that marriages in which only one spouse was ill were at elevated risk of divorce compared with marriages in which both spouse were healthy, but only among marriages in which both spouses reported high levels of marital satisfaction (Wilson and Waddoups 2002). This study represents an important first step in the examination of the potential consequences of illness for divorce in middle and older ages. However, this study suffers from several limitations, most notably that health is assessed with self-rated health rather than with illness diagnosis. While self-rated health measures are highly correlated with objective measures of health (Molarius and Janson 2002), self-rated health measures are also subject to drawbacks, such as gender differences in health-rating styles (Grol-Prokopczyk, Freese, and Hauser 2011) and the role of inputs not specifically related to physical health such as depression (Molarius and Janson 2002) or even marital quality itself, raising concerns of endogeneity.

\section{Variation in the Relationship between IIIness and Marital Dissolution}

Most studies analyzing the effects of health on marital dissolution either have used relatively general measures of health or have examined a single condition; however, different illnesses/ conditions may have different implications for marital dissolution. First, variation in the association of specific illnesses with death (Murphy, Xu, and Kochanek 2013) will impact the relative risks of widowhood versus divorce. Illnesses associated with high mortality risk, such as heart disease, are associated with lower risk of divorce simply because increased mortality risk makes it less likely that both spouses will remain alive, a basic condition for whether the marriage is at risk of divorce or not.

In addition, illnesses also vary in the extent and duration of associated disabilities, which have implications for caregiving burden, work limitations, and curtailment of other life domains. Stroke, for instance, is the leading cause of major long-term disability (Roger et al. 2012) and might create more chronic stressors for a marriage than an illness like cancer, which is often associated with more modest, shorter term disability linked to treatment side effects. Cognitive decline-related disability, which is associated with illnesses such as stroke or heart disease, may be more stressful for caregivers than physical disability alone (Pinquart and Sörensen 2003). In addition, the duration and probability of recovery from a disability may induce variation in the relationship between the associated illness and divorce. Divorce risk might be higher for conditions such as chronic obstructive pulmonary disease (COPD) in which recovery is unlikely and caregiving may extend for many years.

Illnesses also vary in their social meanings, which may have implications for their impact on divorce. Levels of research funding, positive media attention, and societal support vary across conditions and illnesses (Best 2012; Kedrowski and Sarow 2007), with cancer, heart disease, and stroke being the subjects of large public health and advertising campaigns, while illnesses such as COPD - which has a direct association with the stigmatized behavior of smoking (Mannino and Buist 2007) - receive little attention. Such campaigns increase public awareness and popular support for these conditions - which may lessen the emotional burden for couples living with them. But, perhaps as important, they also influence the availability of concrete resources such as support groups, which can play an important role 
in buffering the stress of illness. These differences across health conditions may influence how couples perceive their struggle against an illness and their hopefulness for the future perceptions that may impact their adjustment to care-giving and care-receiving roles.

\section{Gender, Illness, and Marital Dissolution}

Gender may also moderate the relationship between poor health and marital dissolution. A few clinical studies have found higher divorce risks when wives, as opposed to husbands, experience cancer (Glantz et al. 2009; Kirchhoff et al. 2012) or for cancers that affect only women, such as cervical cancer (Carlsen et al. 2007). These findings, however, have been gleaned from relatively young (Kirchhoff et al. 2012) or small samples (Glantz et al. 2009), and are limited to the study of cancer.

Several social processes suggest that middle-aged and older couples may be at greater risk of divorce when wives become ill than when husbands do. First, because sex ratios become increasingly skewed toward women at older ages given women's greater longevity (Austad 2006), and because men tend to marry women younger than they are (Presser 1975), older men are advantaged in the remarriage market by a larger pool of potential partners than is available to older women. Marriage markets are skewed as well by the stronger normative value of youthful beauty for women in that "women are devalued [as potential partners] as they age more than men are" (England and McClintock 2010: 814). Indeed, not only are men much more likely to remarry than women (Shafer and James 2013), the older men are at remarriage, the greater the age gap is with their wives (England and McClintock 2010).

In addition, gender norms regarding the role changes that frequently accompany illness may yield gender differences in the relationship between illness and subsequent divorce. Women are socialized and habituated to caregiving for others across the life course (England 2005), and studies suggest that this extends to caring for ill husbands (Wolff and Kasper 2006). However, caregiving is not fully reciprocated by husbands for sick wives; wives receiving care were more likely to report experiencing gaps in needed caregiving from their spouses than husbands (Allen 1994). Given the gendered nature of caregiving and receiving and caregiving's frequent stressful nature, it is plausible that situations in which ill wives are dependent on husbands for care are more stressful than when wives are caring for ill husbands. On the other hand, illness may be more detrimental in cases where ill husbands must withdraw from employment, given the traditional emphasis on breadwinning for men (Becker 1981). However, as evidenced by Singleton's (2012) study on disability, earnings, and divorce, the importance of breadwinning may be less important at older ages when labor force detachment and declines in earnings for men are more age-normative compared with earlier periods of the life course.

\section{Data and Methods}

\section{Data}

We use data from Waves 1-10 of the RAND HRS data file, a user-friendly, harmonized data set generated from the original HRS files. The Health and Retirement Study (HRS) is an ongoing, nationally-representative, prospective panel study of Americans over the age of 50 
years. Detailed health and socioedemographic information has been collected from respondents and their spouses (regardless of the spouse's age) every two years since 1992. We focus on the original HRS sample in which at least one spouse within the marriage is aged 51-61 at baseline, as prior work has identified this approximate age range where the risk of divorce is highest in the later life course (Brown and Lin 2012).

\section{Analytic Sample}

We construct our analytic sample of marriages based on 9,348 HRS individuals who are married to one another at baseline (Wave 1), yielding 4,674 marriages. As we are interested in the role of serious physical illness onset as a risk factor for marital dissolution, we exclude marriages in which either spouse reports having ever had any of the four chronic conditions of interest at baseline, reducing the sample size to 3,104 marriages. If we were to include those who had ever had any of the serious illnesses of interest, we might be selecting for particularly robust marriages, biasing downwards our estimates of the relationship between illness and divorce. Further, we do not know the date of diagnosis for illness at baseline relative to date of marriage, making it impossible to ascertain the duration of time in which couples lived with illness prior to the study. We also exclude marriages which dissolve either due to divorce/separation or widowhood in the second wave (1994) as it cannot be ensured that our key independent variable, illness onset, in Wave 2 preceded a change in marital status (see Statistical Analysis, below), reducing the sample size to 2,786 marriages. We also exclude those missing information on any covariates (missing data results in a loss of approximately $2.2 \%$ of marriages) or with a weight of zero, yielding a final analytic sample of 2,701 marriages, which correspond to 16,940 wave-to-wave marriage-periods for the pooled illness model. Analyses are weighted using Wave 1 household weights, and clustered at the individual marriage-wave level. Our selection criteria facilitate the identification of the effect of illness onset on marital dissolution, but decrease the representativeness of our sample and thus the generalizability of our findings to all marriages in the sampling frame age range. Though our data are not nationallyrepresentative of all marriages in this age range, our sample does consist of a random sample of marriages in this select healthy population, and thus has a considerable advantage over many other studies examining marital that have relied on convenience samples.

\section{Measures}

Dependent Variable: Marital Dissolution Due to Divorce or Widowhood-The main outcome of interest is whether a Wave 1 marriage ends in divorce or widowhood in a subsequent wave. A marriage was defined to dissolve due to widowhood if either spouse died between consecutive waves and the marriage was intact in the penultimate wave. A marriage was defined to dissolve in divorce if either spouse reported being divorced since the prior wave, or in the rare case that either spouse divorced and remarried between consecutive waves and thus never reported being divorced, if either spouse's total marriage count increased.

Key Independent Variable: Physical Illness Onset of Husband or Wife-The primary independent variable is respondent or spousal illness onset. We focus on the onset of four major life-threatening illnesses: cancer, heart problems, lung disease, and stroke, and 
which together comprise a substantial portion of chronic disease burden in the United States (Murphy, Xu, and Kochanek 2013) and pose a risk for marital dissolution via the death of an individual spouse as well as potentially via divorce. Chronic illness onset measures are based on measures of whether respondent reported a new diagnosis of a particular disease by a doctor since the last interview wave - this enables us to identify the timing of initial illness onset. We examine whether husband or wife experienced the new onset of any of these four conditions (Table 3) as well as the onset of each specific condition modeled simultaneously (Table 4). Illness onset is entered as a time-varying measure and is lagged by one period to ensure that illness onset precedes marital dissolution. The illness onset variable is coded as " 1 " for each subsequent wave in order to acknowledge that the full impacts of illness onset may not be fully experienced until a substantial period of time has elapsed following illness onset. Consistent with prior studies, cancer diagnosis excludes skin cancers. Heart problems include "heart attack, coronary heart disease, angina, congestive heart failure, or other heart problems" and lung disease includes, but is not limited to "chronic lung disease such as chronic bronchitis or emphysema."

Other Baseline Covariates-We also include measures of several factors that prior research has found to be associated with divorce and/or widowhood (via individual mortality). Given the challenges of interpreting time-varying covariates as potential mechanisms for illness onset (see Goodliffe 2003) and for additional substantive reasons (e.g. income typically declines for both sick and well individuals in this age range), none of the covariates listed below are time-varying. These include: age (in years), college education ( $1=$ yes, $0=$ no), race/ethnicity ( $1=$ nonwhite and/or Hispanic, $0=$ White, non-Hispanic), marital duration ( $1=$ less than 10 years, $0=$ more than 10 years), and initial marital satisfaction. Marital satisfaction was ascertained with the following question: "Are you very satisfied, somewhat satisfied, about evenly satisfied and dissatisfied, somewhat dissatisfied, or very dissatisfied with your marriage?" The original assumed-interval measure is retained with "very satisfied" as the reference category for the marital satisfaction measure. Marriages were coded as remarriages if the Wave 1 marriage was a remarriage for either spouse. We also include a measure of husband and wife age differences at baseline; the age difference categories include: wife older by 11 or more years, wife older by five to ten years, wife older by three or four years, husband and wife within two years' age of one another (reference category), husband older by three or four years, husband older by five to ten years, and husband older by 11 or more years.

We also include measures of socioeconomic status: total household income at baseline, total household non-housing assets at baseline, and home ownership at baseline. We include both measures of income and assets as prior research suggests that assets may be an especially important predictor of health at older ages (Robert and House, 1996). We include measures of both total household (non-housing) wealth and home ownership because the former reflects relatively liquid assets at baseline while the latter reflects less liquid assets that represent a substantial component of wealth holdings for many Americans. Missing values for income and assets are imputed by RAND. Household income is based on the sum of husband's and wife's income from earnings, pensions and annuities, Supplemental Security Income and Social Security Disability, Social Security, unemployment and worker's 
compensation, and other government transfers and then coded into quintiles (bottom quintile is reference). Non-housing assets are coded into five categories: negative wealth (i.e. debt); $\$ 0-\$ 50,000$ (reference category); $\$ 50,000-\$ 100,000 ; \$ 100,000-\$ 250,000$; and $\$ 250,000$ or more. We also include dichotomous indicators for health insurance for both husband and wife.

Due to collinearity, we were unable to simultaneously model both spouses' education, race/ ethnicity, or marital satisfaction. Models presented use husband's education and race/ ethnicity and wife's marital satisfaction, as there is less missing data for wife's reports of marital satisfaction and there is also more variation in martial satisfaction among wives compared with husbands (not shown). Additional analysis (not shown) indicates that results do not differ if wife's race/ethnicity or education is used instead of husband's or if husband's marital satisfaction is used.

\section{Statistical Analysis}

To assess risk of marital dissolution, we estimate a series of discrete-time event history models with competing events using multinomial logistic regression. Divorce/separation (referred to as "divorce" hereafter) or widowhood are be modeled as competing events, as marriages with at least one spouse in the HRS age range are risk for both divorce and widowhood. The continuously married category is the reference category. We employ a closed cohort design in which Wave 1 marriages are followed until the marriage dissolves or is censored. We focus on the cohort of Wave 1 marriages since this is the only time period in which marital satisfaction — a key covariate of interest—is collected. We generate a marriage-period dataset in which each marriage contributes a marriage-period until marital dissolution occurs or until the marriage is censored. A marriage is defined as censored if the Wave 1 marriage remains intact through 2010, or if either spouse misses a wave. For marriages in which spouses differed in the number of waves they participated in the survey, the minimum observation length of the two spouses was taken and the marriage was subsequently coded as censored. Marriages are not followed after a wave is missed, as critical information (e.g. new illness onset) is missing and is difficult to impute. Additional analysis of survey attrition reveals that many marriages attrit (939 marriages out of 2,701 total, or $34.8 \%$ - see Table 2). Though attrition is considerable, the analytic decision to include marriages in the risk set until attrition maximizes available information compared with, say, deletion of couples that ever-attrit. Furthermore, prior research has noted that attrition rates for a two-person household in HRS is nearly identical to a one-person household (Banks, Muriel, and Smith 2011), which suggests that the attrition in our sample was not significantly altered by using either spouse's attrition status. Period (length of observation) was included as both a linear and quadratic term, as results from log likelihood ratio tests suggested including both linear and quadratic terms had better model fit compared with only including the linear term (not shown). These linear and quadratic period terms can alternatively be interpreted as reflecting the aging of husbands and wives, controlling for their baseline age. We present results both as log odds and as marginal effects with other covariates held at their means, which can be interpreted as probabilities (Long and Freese 2006).

J Health Soc Behav. Author manuscript; available in PMC 2016 September 01. 


\section{Results}

Descriptive statistics are displayed in Table 1. Marriages are much more likely to end by widowhood than divorce. Twenty four percent of marriages dissolve due to widowhood, compared with $6 \%$ due to divorce. In addition, there is considerable attrition over the 18 years of the study $-35 \%$ of marriages attrit before the end of the study period-more than are lost via widowhood and divorce combined. The distribution of initial illness onset for husbands and wives, as well as timing of divorce and widowhood by wave can be found in Table 2. Not surprisingly, there is a substantial amount of new chronic illness onset (cancer, heart problems, lung disease, and/or stroke) among husbands and wives (Table 2) within marriages. Consistent with prior research, we observe an increase in physical illness incidence across waves (as husbands and wives age) and husbands experience higher illness incidence than wives. Looking at the distribution of divorce and widowhood by wave, we see that widowhood is a more common pathway out of marriage than divorce in all waves.

Table 3 displays multinomial logistic regression models predicting marital dissolution due to divorce or widowhood as a function of onset of any of the four illnesses (cancer, heart problems, lung disease, and/or stroke). Husband's illness onset is not associated with subsequent divorce compared with remaining married. In contrast, wife's illness onset is positively associated with $1 \%$ higher probability of subsequent divorce compared with remaining married. However, we fail to reject a test of the null hypothesis that the coefficients for husband's illness onset and wife's illness onset are equal ( $\mathrm{p}=0.1532)$. This post-hoc test represents a formal test of a gender difference in the relationship of illness onset and divorce, and we may fail to reject due to the fact that divorce is relatively rare. In addition, we find that poor baseline marital satisfaction is positively associated with subsequent divorce, as is husband being much (11 years or more) older than wife. Husband's health insurance is protective against divorce. The statistically significant negative period quadratic term indicates nonlinearity in the risk of divorce over the study period. More specifically, consistent with prior work, the risk of divorce decreases with long periods of marital duration.

Turning to the risk of subsequent widowhood versus remaining married, we see that husband's illness onset is associated with five percent higher probability of widowhood and wife's illness onset is associated with four percent higher probability of widowhood compared with staying married. As for divorce, we fail to reject a test of the null hypothesis that the coefficients for husband's illness onset and wife's illness onset are equal. Husband age is positively associated with widowhood, which may reflect dimensions of health not captured by the chronic disease onset measure. High levels of non-housing assets are protective against widowhood at the $\mathrm{p}<0.05$ level, as is home ownership at the $\mathrm{p}<0.10$ level. Marriages in which wives are five to 10 years older than husbands are also more likely to dissolve via widowhood. Finally, the (positive) linear and (negative) quadratic period terms are also statistically significant, indicating that marital dissolution via widowhood increases with time, but at a slower rate as time elapses.

Next we turn to illness-specific (with separate indicators for cancer, heart problems, lung disease, and stroke) associations with marital dissolution in Table 4. Neither husband's nor 
wife's cancer or lung disease onset is associated with subsequent divorce. Wife's heart problems onset (but not husband's) is positively associated with a two percent higher probability of subsequent divorce compared with staying married. Further, we reject a null hypothesis of the equality of the heart problem onset coefficients for husband and wife at the $\mathrm{p}<0.05$ level, providing robust support that the relationship between heart problem onset and divorce is gendered. Wife's stroke onset is positively associated with a three percent higher probability of divorce compared with staying married, however this association is not statistically significantly different from the coefficient for husband's stroke ( $\mathrm{p}=0.3818)$, which is itself not statistically significant. Associations between other covariates and divorce and consistent with the results presented in Table 3.

Looking at marital dissolution due to widowhood, we see that neither husband's nor wife's cancer diagnosis is associated with elevated risk of widowhood, nor are husband's heart problems onset or wife's stroke onset. Wife's heart problems onset is associated with a six percent higher probability of marital dissolution via widowhood compared with remaining married. Husband's lung disease onset is associated with eight percent higher probability of widowhood, and wife's lung disease onset is associated with seven percent higher probability of widowhood compared with remaining married, though the relationship for wives is only marginally significant. Husband's stroke onset is marginally statistically significantly associated with five percent higher probability of widowhood. We fail to reject the null hypothesis of equality of coefficients by gender for each specific illness.

Associations between other covariates and widowhood are quite similar to results presented in Table 3.

\section{Supplementary Analysis}

We also conducted several supplementary analyses. First, we conducted a first-differences pooled ordinary least squares model (estimating the linear probability of divorce versus remaining married) to assess the robustness of our results to unobserved time-invariant variables that might be correlated with our observed covariates and thus bias our results. Our first differences estimate of the probability of divorce following wife's illness onset was not statistically significant. Thus, we conclude that our findings are not robust to unobserved time-invariant variables. This suggests that unobserved characteristics—such as marital commitment-may impact the relationship between illness and subsequent divorce risk. We also looked at Catholic religious identity of husband and/or wife as well as whether either (or both spouses) have children. Neither Catholic identity nor the number of children predicted divorce at the $p<0.05$ level when added to the panel of covariates examined in main analyses, and the main substantive findings remained unchanged. In addition, we included controls for husband's and wife's baseline self-rated health, as there may be meaningful physical health variation not captured by the absence of ever-diagnosis of the focal physical illnesses at baseline. Again, our substantive findings remain unchanged, though the self-rated health of both partners independently predicts widowhood. We also included baseline smoking status as a covariate which did not change substantive findings, though both husband's and wife's current smoking also predict marital dissolution due to widowhood. We also tested for interactions between illness onset and a variety of other covariates including marital satisfaction, race/ethnicity, and education added to the model 
with main effects. Interactions were not statistically significant. Finally, we re-ran our main analyses without weights; results were substantively quite similar.

\section{Discussion}

The present study examined whether illness onset constituted a risk factor for marital dissolution at middle and older ages. In our analysis examining the onset of any of four serious illnesses (cancer, heart problems, lung disease, and/or stroke), we find that only wife's illness onset is associated with elevated risk of divorce, while either husband or wife's illness onset is associated with elevated risk of widowhood. Though results from hypothesis tests do not allow us to say that that wife's illness onset of any of the four serious disease examined is a stronger predictor of divorce than husband's illness onset, our focus on illness and divorce in middle and older ages contributes to understanding the risk factors for divorce in later life, which constitute a growing share of all divorces (Brown and Lin 2012). Still, it is important to acknowledge that the majority of divorces occur earlier in life, when illness is much rarer (and less normative), which may make it more stressful to marriages. Recent work examining marriages among younger people found that husbands'

-but not wives' - work-limiting health conditions was associated with elevated divorce risk (e.g., Teachman 2010), which may reflect the relatively greater emphasis of employment for spouses-especially husbands-earlier in the life course. Taken together, the present study and prior work point to the importance of contextualizing divorce risk factors within a life course framework and in conjunction with other factors, such as race and class. Further, given greater economic symmetry between spouses in more recent cohorts, birth cohort as well as age may alter the extent to which spouse's gender modifies illness onset as a risk factor for divorce.

Prior work has suggested that the better health of the married is not just due to the healthier selecting into marriage, but beneficial social processes (i.e., social causation) occurring within marriages, such as spouses encouraging one another in healthy lifestyle practices (Umberson 1992). Our work indicates that health selection processes should not be discounted and should be considered more carefully on both conceptual and methodological grounds in future research. Specifically, researchers should consider how health operates as a stressor on marriages, and should exercise caution in interpreting cross-sectional studies as evidence of the benefits of marriage. Further, these selection processes are gendered in nature. Women are vulnerable to marital dissolution in the face of illness through both widowhood and divorce. Women are more likely to experience widowhood than men. Women's greater longevity compared with men's (Austad 2006) and the typical partnering of women with men who are older than them (England and McClintock 2010) mean that married women are likely to survive their husbands. Our work indicates that women's own health also has consequences for marital dissolution as women's own illness (but not their husband's illness) elevates their risk of divorce. Both widowhood and divorce in turn have large consequences for health (Hughes and Waite 2009; Williams and Umberson 2004).

Turning to specific illnesses, we find some evidence that the relationship between illness onset and divorce varies by specific illness. Wife's (lagged) heart problems onset and stroke onset are both statistically significant positive predictors of divorce, while none of the

J Health Soc Behav. Author manuscript; available in PMC 2016 September 01. 
measures of husband's illness onset are associated with divorce. In addition, we reject the null hypothesis of equality of coefficients for husband's heart problems onset and wife's heart problems onset $(\mathrm{p}<0.05)$. This provides stronger evidence that the association between heart problems and divorce depends on the gender of the spouse who becomes ill. Prior work has shown that the physiological symptoms of aspects of cardiovascular disease such as heart attacks vary by gender (Reidinger et al. 2001). Our work suggests that the impacts of cardiovascular disease on marriage, at least in the case of divorce, also vary by gender. Our finding that cancer onset was not associated with divorce is in contrast to prior clinical studies which found elevated divorce risks for reproductive cancers (Carlsen et al. 2007; Syse and Kravdal 2007). Besides concerns about selection issues and differently aged samples, our lack of findings for cancer may reflect further variation within the experience of cancer, though a more fine-grained analysis by type of cancer also comes at an additional cost to statistical power.

Prior research highlights variations in illness experience by gender, which may influence risk of divorce for wives and husbands. For example, women often report more symptoms, pain, and depressive symptoms following the onset of chronic illness (Stanton, Revenson, and Tennen 2007). Differences in illness experiences among men and women may reflect variation in biological and social processes in relation to the specific illness. Regarding stroke, wife's onset was predictive of subsequent divorce, while husband's was not. Though we failed to reject equality of the stroke coefficients for husband and wife, prior work supports the notion that stroke may be more stressful among wives than husband, as women have poorer functional health outcomes following stroke than men (Petrea et al. 2009).

Like any study there are caveats to our work. First, in sensitivity analysis, we found that the relationship between wife's illness and subsequent divorce was not statistically significant when we accounted for unobserved time-invariant characteristics using a first differences model. While this raises cautions as to the causal effect of illness on divorce, it highlights a critical issue regarding the complex dynamics between health, marital stability, and other unobserved factors such as commitment to the idea of marriage. More broadly, this finding highlights the importance of considering selection and unobserved heterogeneity in assessing the relationship between marriage and health. In addition, time-varying characteristics likely also would impact the interpretation of our findings. For example, while we restricted the sample to marriages in which both spouses were free of the illnesses of interest at baseline, it possible that marital quality dynamics over time influenced the development and management of illnesses prior in important ways we could not fully account for in the observational window and with available measures. We attempted to address this limitation in supplementary analysis by controlling for husband's and wife's self-rated health, but unobserved heterogeneity cannot be eliminated, nor can we account for marital quality dynamics either before or after Wave 1. An additional limitation pertains to the reliance of respondent reports of physician diagnosis to establish chronic illness onset. Namely, the issue is that diagnosis is not synonymous with actual onset and is conditional on medical care access, health literacy, and recall. As such, our measures may underestimate illness onset, biasing our estimates of the relationship between illness and divorce downwards. However, we believe that while this is a limitation of our health measures, it does not pose a serious threat to our results. First, the conditions examined-cancer, heart 
problems including heart attack, lung disease including "chronic lung disease such as chronic bronchitis or emphysema," and stroke are quite serious conditions that frequently require individuals to seek medical care and are likely quite memorable personal experiences. Second, surveys are conducted every two years, reducing respondent recall burden. Finally, we account for (baseline) health insurance, which is a good proxy for health care access. In fact, health insurance access among husbands is independently associated with a lower risk of divorce. Taken together with recent work (Sohn 2015) on the protective role of obtaining health insurance via a spouse (especially a husband) against divorce, this finding highlights how an additional aspect of health care-health insurance-impacts gendered risk factors for divorce.

Another limitation of this research is the reliance of self-reported marital status. Prior research has noted that marital status is misreported; however, it is most often misreported by divorced individuals with deceased former spouses (Weaver 2000). This suggests that the divorce among our sample may be underestimated, while widowhood may be overestimated. In addition, our data does not permit us to observe which spouse initiates divorce. Prior work, mostly examining younger Americans, finds that about two-thirds of divorces are initiated by women (Brinig and Allen 2000). The gendered nature of marriage markets at older ages which privilege men suggests that men would be more likely to initiate divorce following wife's illness because men have more options for new partnerships than women. On the other hand, however, sick wives who are not receiving adequate care from their husbands might rather divorce than remain married to a poor caregiver. In addition, we cannot differentiate between cohort, period, and age effects. The recent finding that divorce in middle and older ages has been increasing likely reflects a combination of factors, including the aging of cohorts with more favorable attitudes towards divorce, the experience of divorce earlier in the life course as a fairly normative event, and improvements in medical care that benefit all older adults. Further, we do not examine age variation within the "middle and older ages" group. For many conditions, illness onset becomes increasingly normative as individuals age. The normative timing of illness onset in the later life course may make illness less stressful for individuals, as well as decrease the availability of (at least similarly aged) relatively healthy potential mates.

Finally, substantial (35\%) attrition occurred over the course of the study; however, previous research has noted that prior health and illness status does not significantly impact attrition rates in the HRS (Banks, Muriel, and Smith 2011). Moreover, Michaud et al. (2006) find that respondents who temporarily attrit (i.e., return to the survey at a later date) in the HRS are noticeably different from non-attritors and respondents who completely attrit, which suggests excluding temporary attritors may make our sample less biased. Additionally, Michaud and van Soest (2008) observed an attrition rate of approximately 10\% per wave (or $5 \%$ annually) among married couples in the original HRS cohort. Given our risk group criteria (i.e., healthy couples), our attrition rate corresponds with previous estimates. While prior health status does not appear to influence attrition rates, socioeconomic status has been shown to influence response rates and retention in the HRS (Banks, Muriel, and Smith 2011); therefore, any selection effect from attrition would most likely bias downward both estimates of the relationship between illness onset and both divorce and widowhood to the 
extent that lower-SES couples are more vulnerable to divorce and death in the face of health problems.

This work suggests several avenues for future research. First, future work should examine the roles of caregiving, income loss, and labor force detachment as mechanisms linking illness with subsequent divorce. Additional studies should also examine other dimensions of health and well-being as risk factors for divorce. Recent work, for example, found that sexual activity and psychological well-being were important mediators of the relationship between physical health decline and declines in marital quality (Galinsky and Waite 2014). Future work should also differentiate between illness diagnosis and disability, as the consequences of illness onset may operate both through the social stigma of diagnosis as well as through the disabling process associated with many illnesses.

Our findings suggest that older women's health experiences impact their risk of divorce. Other research has shown that following chronic illness onset, women often report more physical and psychological distress, which may directly or indirectly influence divorce risk. Nevertheless, married women diagnosed with a serious health condition may find themselves at increased risk of divorce and may have to manage disease sequelae while experiencing the stressors associated with divorce. These women may be particularly vulnerable for further health declines considering the negative health consequences associated with marital dissolution. While it may not be as great of a concern for older women (especially over the age of 65 years eligible for Medicare), previous research has noted that following divorce women often experience health insurance loss (Lavelle and Smock 2012). Post-divorce women who do not qualify for public coverage or must switch coverage - to either public or private health insurance-may lose access to healthcare when it is needed most. Given the increasing concern of the aging population and healthcare costs, policymakers should be aware of relationship between disease and risk of divorce.

\section{Acknowledgments}

Thank you to Samuel Isaacson, Dustin Brown, Sarah Burgard, James House, I-Fen Lin, and Susan Brown for helpful advice and productive conversations. We are also grateful to N.E. Barr for editorial assistance. This study was supported by a National Institute on Aging training grant to the Population Studies Center at the University of Michigan (T32 AG000221).

\section{References}

Allen, Susan M. Gender Differences in Spousal Caregiving and Unmet Need for Care. Journals of Gerontology. 1994; 49(4):S187-S195. [PubMed: 8014402]

Amato, Paul M. Research on Divorce: Continuing Trends and New Developments. Journal of Marriage and Family. 2010; 72(3):650-666.

Austad, Steven N. Why Women Live Longer than Men: Sex Differences in Longevity. Gender Medicine. 2006; 3(2):79-92. [PubMed: 16860268]

Banks J, Muriel A, Smith JP. Attrition and health in ageing studies: evidence from ELSA and HRS. Longitudinal and life course studies. 2011;2(2)

Becker, Gary S. A Treatise on the Family. Cambridge, MA: Harvard University Press; 1981.

Best, Rachel Kahn. Disease Politics and Medical Research Funding: Three Ways Advocacy Shapes Policy. American Sociological Review. 2012; 77(5):780-803. 
Brinig, Margaret; Allen, Douglas W. These Boots Are Made for Walking: Why Most Divorce Filers Are Women. American Law and Economics Review. 2000; 2(1):126-169.

Brown, Susan L.; Lin, I-Fen. The Gray Divorce Revolution: Rising Divorce Among Middle-Aged and Older Adults, 1990-2010. Journals of Gerontology Series B: Psychological Sciences and Social Sciences. 2012; 67(6):731-741.

Byrne, Julianne; Fears, Thomas R.; Steinhorn, Sandra C.; Mulvihill, John J.; Connelly, Roger R.; Austin, Donald F.; Holmes, Grace F.; Holmes, Frederick F.; Latourette, Howard B.; Jane Teta, M.; Strong, Louise C.; Myers, Max H. Marriage and Divorce after Childhood and Adolescent Cancer. JAMA. 1989; 262(19):2693-2699. [PubMed: 2810602]

Carlsen, Kathrine; Dalton, Susanne Oksbjerg; Frederiksen, Kirsten; Diderichsen, Finn; Johansen, Christoffer. Are Cancer Survivors at an Increased Risk for Divorce? A Danish Cohort Study. European Journal of Cancer. 2007; 43(14):2093-2099. [PubMed: 17627811]

Charles, Kerwin Kofi; Stephens, Melvin. Job Displacement, Disability, and Divorce. Journal of Labor Economics. 2004; 22(2):489-522.

Choi, Heejeon; Marks, Nadine F. Transition to Caregiving, Marital Disagreement, and Psychological Well-Being: A Prospective National Study. Journal of Family Issues. 2006; 27(12):1701-1722.

Crimmins, Eileen M. Trends in the Health of the Elderly. Annual Review of Public Health. 2004; 25:75-98.

Crimmins, Eileen M.; Beltrán-Sánchez, Hiram. Mortality and Morbidity Trends: Is There Compression of Morbidity? Journals of Gerontology Series B: Psychological Sciences and Social Sciences. $2011 ; 66(1): 75-86$.

Daniel, Katie; Wolfe, Charles DA.; Busch, Markus A.; McKevitt, Christopher. What Are the Social Consequences of Stroke for Working-Aged Adults?: A Systematic Review. Stroke. 2009; 40(6):e431-e440. [PubMed: 19390074]

England, Paula. Emerging Theories of Care Work. Annual Review of Sociology. 2005; 31:381-399.

England, Paula; McClintock, Elizabeth Aura. The Gendered Double Standard of Aging in Marriage Markets. Population and Development Review. 2010; 35(4):797-816.

Fikkan, Janna L.; Rothblum, Esther D. Is Fat a Feminist Issue? Exploring the Gendered Nature of Weight Bias. Sex Roles. 2012; 66(9-10):575-592.

Galinsky, Adena; Waite, Linda. Sexual Activity and Health as Mediators of the Relationship between Physical Health and Marital Quality. Journals of Gerontology Series B: Psychological Sciences and Social Sciences. 2014; 69(3):482-492.

Gortmaker, Steven L.; Must, Aviva; Perrin, James M.; Sobol, Arthur M.; Dietz, William H. Social and Economic Consequences of Overweight in Adolescence and Young Adulthood. New England Journal of Medicine. 1993; 329(14):1008-1012. [PubMed: 8366901]

Glantz, Michael J.; Chamberlain, Marc C.; Liu, Qin; Hsieh, Chung-Cheng; Edwards, Keith R.; Van Horn, Alixis; Recht, Lawrence. Gender Disparity in the Rate of Partner Abandonment in Patients with Serious Medical Illness. Cancer. 2009; 115(22):5237-5242. [PubMed: 19645027]

Goodliffe, Jay. The Hazards of Time-Varying Covariates. 2003. Unpublished paper

Grol-Prokopczyk, Hanna; Freese, Jeremy; Hauser, Robert M. Using Anchoring Vignettes to Assess Group Differences in General Self-Rated Health. Journal of Health and Social Behavior. 2011; 52(2):246-261. [PubMed: 21673148]

Hughes, Mary Elizabeth; Waite, Linda J. Marital Biography and Health at Mid-Life. Journal of Health and Social Behavior. 2009; 50(3):344-358. [PubMed: 19711810]

Joung, Inez MA.; Dike van de Mheen, H.; Stronks, Karien; van Poppel, Frans WA.; Mackenbach, Johan P. A Longitudinal Study of Health Selection in Marital Transitions. Social Science and Medicine. 1998; 46(3):425-35. [PubMed: 9460823]

Kedrowski, Karen; Sarow, Marilyn. Cancer Activism: Gender, Media, and Public Policy. Chicago: University of Illinois Press; 2007.

Kirchhoff, Anne C.; Yi, Jaehee; Wright, Jennifer; Warner, Echo L.; Smith, Ken R. Marriage and Divorce among Young Adult Cancer Survivors. Journal of Cancer Survivors. 2012; 6(4):441-450.

Lavelle, Bridget; Smock, Pamela J. Divorce and Women's Risk of Health Insurance Loss. Journal of Health and Social Behavior. 2012; 53(4):413-431. [PubMed: 23147653]

J Health Soc Behav. Author manuscript; available in PMC 2016 September 01. 
Lillard, Lee A.; Waite, Linda J. Till Death Do Us Part: Marital Disruption and Mortality. American Journal of Sociology. 1995; 100(5):1131-56.

Long, J Scott; Freese, Jeremy. Regression Models for Categorical Outcomes using Stata, Second Edition. College Station, TX: Stata Press; 2006.

Mannino, David M.; Buist, Sonia. Global Burden of COPD: Risk Factors, Prevalence, and Future Trends. The Lancet. 2007; 370:765-773.

Michaud, Pierre-Carl; Van Soest, Arthur. Health and Wealth of Elderly couples: Causality Tests Using Dynamic Panel Data Models. Journal of Health Economics. 2008; 27(5):1312-1325. [PubMed: 18513809]

Michaud, Pierre-Carl; Kapteyn, Arie; Smith, James P.; Van Soest, Arthur. Temporary and Permanent Unit Non-response in Follow-up Interviews of the Health and Retirement Study. Longitudinal and Life Course Studies. 2011; 2(2):145-169.

Molarius, Anu; Janson, Staffan. Self-Rated Health, Chronic Diseases, and Symptoms among MiddleAged and Elderly Men and Women. Journal of Clinical Epidemiology. 2002; 55(4):364-370. [PubMed: 11927204]

Murphy, Sherry L.; Xu, Jiaquan; Kochanek, Kenneth D. National Vital Statistics Reports. Vol. 61. Hyattsville, MD: National Center for Health Statistics; 2013. Deaths: Final Data for 2010. Available from: http://www.cdc.gov/nchs/data/nvsr/nvsr61/nvsr61_04.pdf

Petrea, Rodica E.; Beiser, Alexa S.; Seshadri, Sudha; Kelly-Hayes, Margaret; Kase, Carlos S.; Wolf, Philip A. Gender Differences in Stroke Incidence and Poststroke Disability in the Framingham Heart Study. Stroke. 2009; 40(4):1032-1037. [PubMed: 19211484]

Pinquart, Martin; Sörensen, Silvia. Associations of Stressors and Uplifts of Caregiving With Caregiver Burden and Depressive Mood: A Meta-Analysis. Journals of Gerontology: Psychological Sciences. 2003; 58(2):P112-P128.

Presser, Harriet B. Age Differences between Spouses: Trends, Patterns, and Social Implications. American Behavioral Scientist. 1975; 19(2):190-205.

Riedinger, Mary S.; Dracup, Kathleen A.; Brecht, Mary-Lynn; Padilla, Geraldine; Sarna, Linda; Ganz, Patricia A. Quality of life in patients with heart failure: do gender differences exist? Heart \& Lung: The Journal of Acute and Critical Care. 2001; 30(2):105-116. [PubMed: 11248713]

Robert, Stephanie A.; House, James S. SES differentials in health by age and alternative indicators of SES. Journal of Aging and Health. 1996; 8(3):359-388. [PubMed: 10165980]

Roger, Véronique L.; Go, Alan S.; Lloyd-Jones, Donald M.; Benjamin, Emelia J.; Berry, Jarett D.; Borden, William B.; Bravata, Dawn M.; Dai, Shifan; Ford, Earl S.; Fox, Caroline S.; Fullerton, Heather J.; Gillespie, Cathleen; Hailpern, Susan M.; Heit, John A.; Howard, Virginia J.; Kissela, Brett M.; Kittner, Steven J.; Lackland, Daniel T.; Lichtman, Judith H.; Lisabeth, Lynda D.; Makuc, Diane M.; Marcus, Gregory M.; Marelli, Ariane; Matchar, David B.; Moy, Claudia S.; Mozaffarian, Dariush; Mussolino, Michael E.; Nichol, Graham; Paynter, Nina P.; Soliman, Elsayed Z.; Sorlie, Paul D.; Sotoodehnia, Nona; Turan, Tanya N.; Virani, Salim S.; Wong, Nathan D.; Woo, Daniel; Turner, Melanie B. Heart Disease and Stroke Statistics-2012 Update: A Report from the American Heart Association. Circulation. 2012; 125:e2-220. [PubMed: 22179539]

Schulz, Richard; Beach, Scott R. Caregiving as a Risk Factor for Mortality. Journal of the American Medical Association. 1999; 282(23):2215-2219. [PubMed: 10605972]

Shafer, Kevin; James, Spencer L. Gender and Socioeconomic Status Differences in First and Second Marriage Formation. Journal of Marriage and Family. 2013; 75(3):544-564.

Singleton P. Insult to Injury Disability, Earnings, and Divorce. Journal of Human Resources. 2012; 47(4):972-990.

Smith, James P.; Smith, Gillian C. Long-Term Economic Costs of Psychological Problems during Childhood. Social Science and Medicine. 2010; 71(1):110-115. [PubMed: 20427110]

Sohn H. Health Insurance and Risk of Divorce: Does Having Your Own Insurance Matter? Journal of Marriage and Family. 201510.1111/jomf.12195

Stanton, Annette L.; Revenson, Tracey A.; Tennen, Howard. Health Psychology: Psychological Adjustment to Chronic Disease. Annual Review Psychology. 2007; 58:565-592.

Stevenson, Betsey; Wolfers, Justin. Marriage and Divorce: Changes and their Driving Forces. Journal of Economic Perspectives. 2007; 21(2):27-52. 
Syse, Astri; Kravdal, Øystein. Does Cancer Affect the Divorce Rate? Demographic Research. 2007; 16:469-492.

Teachman, Jay. Work-Related Health Limitations, Education, and the Risk of Marital Disruption. Journal of Marriage and Family. 2010; 72(4):919-932.

Uhlenberg, Peter; Myers, Mary Anne P. Divorce and the Elderly. The Gerontologist. 1981; 21(3):276282. [PubMed: 7239255]

Umberson, Debra. Gender, Marital Status, and the Social Control of Health Behavior. Social Science and Medicine. 1992; 34(8):907-17. [PubMed: 1604380]

Weaver DA. The Accuracy of Survey-Reported Marital Status: Evidence from Survey Records Matched to Social Security Records. Demography. 2000; 37(3):395-399. [PubMed: 10953812]

Williams, Kristi; Umberson, Debra S. Marital Status, Marital Transitions, and Health: A Gendered Life Course Perspective. Journal of Health and Social Behavior. 2004; 45(1):81-98. [PubMed: 15179909]

Wilson, Sven E.; Waddoups, Shawn L. Good Marriages Gone Bad: Health Mismatches as a Cause of Later-Life Marital Dissolution. Population Research and Policy Review. 2002; 21(6):505-533.

Weiss, Yoram; Willis, Robert J. Match Quality, New Information, and Marital Dissolution. Journal of Labor Economics. 1997; 15(1):S293-S329.

Wolff, Jennifer L.; Kasper, Judith D. Caregivers of Frail Elders: Updating a National Profile. The Gerontologist. 2006; 46(3):344-356. [PubMed: 16731873]

Yorgason, Jeremy B.; Booth, Alan; Johnson, David. Health, Disability, and Marital Quality: Is the Association Different for Younger Versus Older Cohorts? Research on Aging. 2008; 30(6):623648.

\section{Biographies}

Amelia Karraker is an Assistant Professor in Human Development and Family Studies at Iowa State University. Her research focuses on health inequalities and the intersections between marriage, socioeconomic status, and health across the life course. She is particularly interested in the social and psychological mechanisms that underpin health inequalities as well as gendered experiences in aging.

Kenzie Latham is an Assistant Professor of Sociology at Indiana University-Purdue University Indianapolis (IUPUI). Her research interests include health and aging with an emphasis on chronic illness and functional health. Much of Latham's research focuses on identifying and understanding health disparities among older adults.

J Health Soc Behav. Author manuscript; available in PMC 2016 September 01. 
Table 1

Analytic Sample Weighted Baseline Descriptive Statistics, Health and Retirement Study (1992-2010), $(n=2,701$ marriages)

\begin{tabular}{|c|c|c|c|}
\hline & Mean/Proportion & SE & Range \\
\hline \multicolumn{4}{|l|}{ Marriage Status at Final Intereview (Unweighted) } \\
\hline Remaining Married & 0.36 & & \\
\hline Divorced & 0.06 & & \\
\hline Widowed & 0.24 & & \\
\hline Attrition of one or both spouses & 0.35 & & \\
\hline Husband Age (years) & 56.73 & 0.12 & $(25-92)$ \\
\hline Wife Age (years) & 52.78 & 0.12 & $(29-71)$ \\
\hline Husband College-Educated & 0.27 & 0.01 & \\
\hline Husband non-White and/or Hispanic & 0.14 & 0.01 & \\
\hline Wife's Report of Marital Satisfaction & 4.76 & 0.01 & $(1-5)$ \\
\hline Remarriage & 0.33 & 0.01 & \\
\hline Marital Duration Less Than 10 Years & 0.11 & 0.01 & \\
\hline Husband Has Health Insurance & 0.79 & 0.01 & \\
\hline Wife Has Health Insurance & 0.79 & 0.01 & \\
\hline \multicolumn{4}{|l|}{ Household Income Quintiles } \\
\hline 1 & & \multicolumn{2}{|c|}{$\$ 0-\$ 20,900$} \\
\hline 2 & & \multicolumn{2}{|c|}{$\$ 21,000-\$ 34,800$} \\
\hline 3 & & \multicolumn{2}{|c|}{$\$ 35,000-\$ 48,990$} \\
\hline 4 & & \multicolumn{2}{|c|}{$\$ 49,000-\$ 69500$} \\
\hline 5 & & \multicolumn{2}{|c|}{$\$ 70,000-\$ 600,000$} \\
\hline \multicolumn{4}{|l|}{ Household Non-Housing Assets } \\
\hline In Debt & 0.03 & 0.00 & \\
\hline$\$ 0-\$ 50,000$ & 0.40 & 0.01 & \\
\hline$\$ 50,000-\$ 100,000$ & 0.18 & 0.01 & \\
\hline$\$ 100,000-\$ 250,000$ & 0.19 & 0.01 & \\
\hline More than $\$ 250,000$ & 0.20 & 0.01 & \\
\hline Home Ownership & 0.90 & 0.01 & \\
\hline \multicolumn{4}{|l|}{ Spousal Age Difference } \\
\hline Wife 11 years older or more & 0.01 & 0.00 & \\
\hline Wife 5 to 10 years older & 0.04 & 0.00 & \\
\hline Wife 3 or 4 years older & 0.03 & 0.00 & \\
\hline Husband and Wife within 2 years of one another & 0.33 & 0.01 & \\
\hline Husband 3 or 4 years older & 0.20 & 0.01 & \\
\hline Husband 5 to 10 Years Older & 0.29 & 0.01 & \\
\hline Husband 11 years older or more & 0.10 & 0.01 & \\
\hline
\end{tabular}

Note: Analysis are weighted using Wave 1 household weights unless otherwise noted.

$J$ Health Soc Behav. Author manuscript; available in PMC 2016 September 01. 


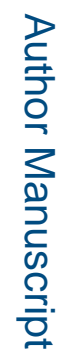
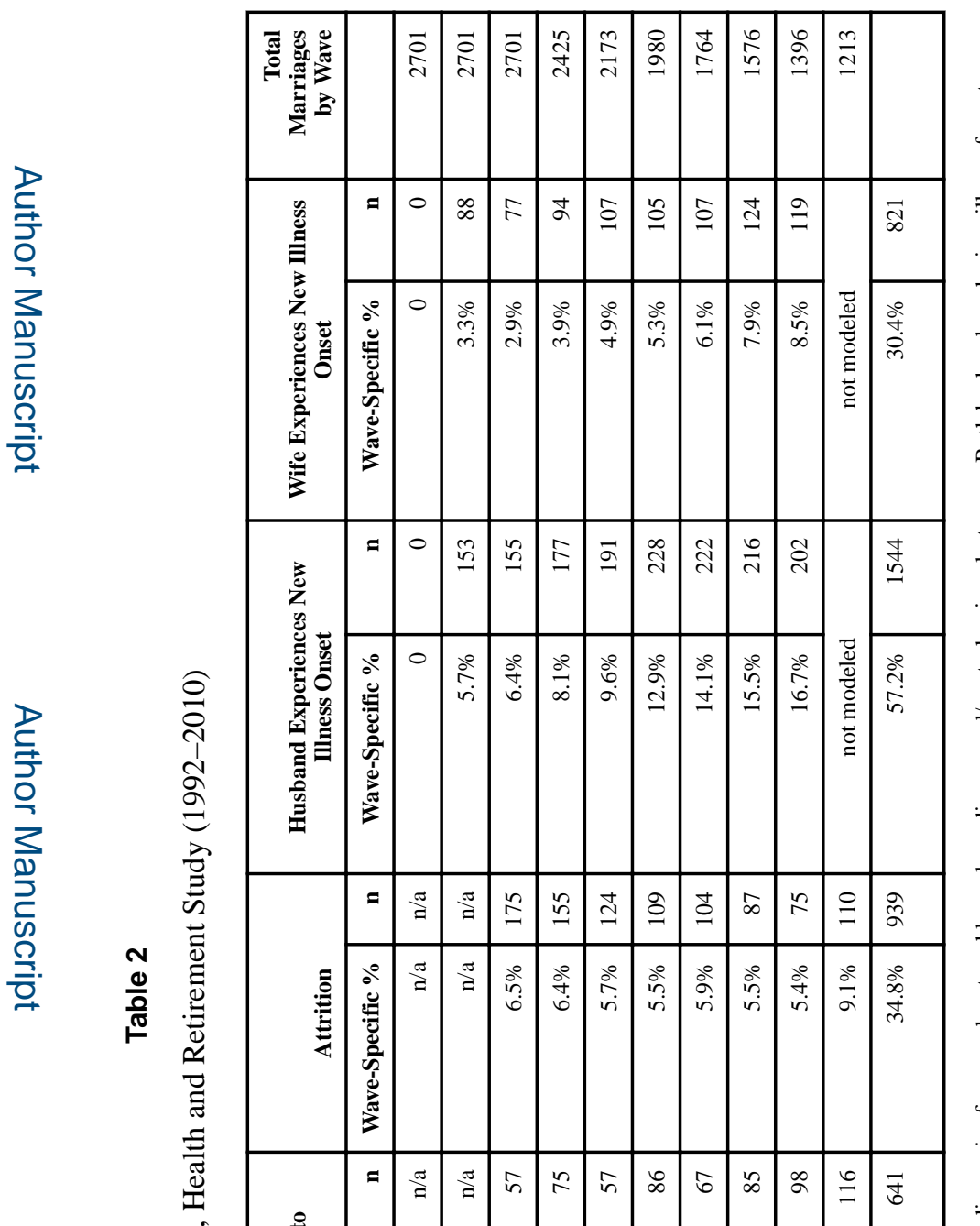

로을

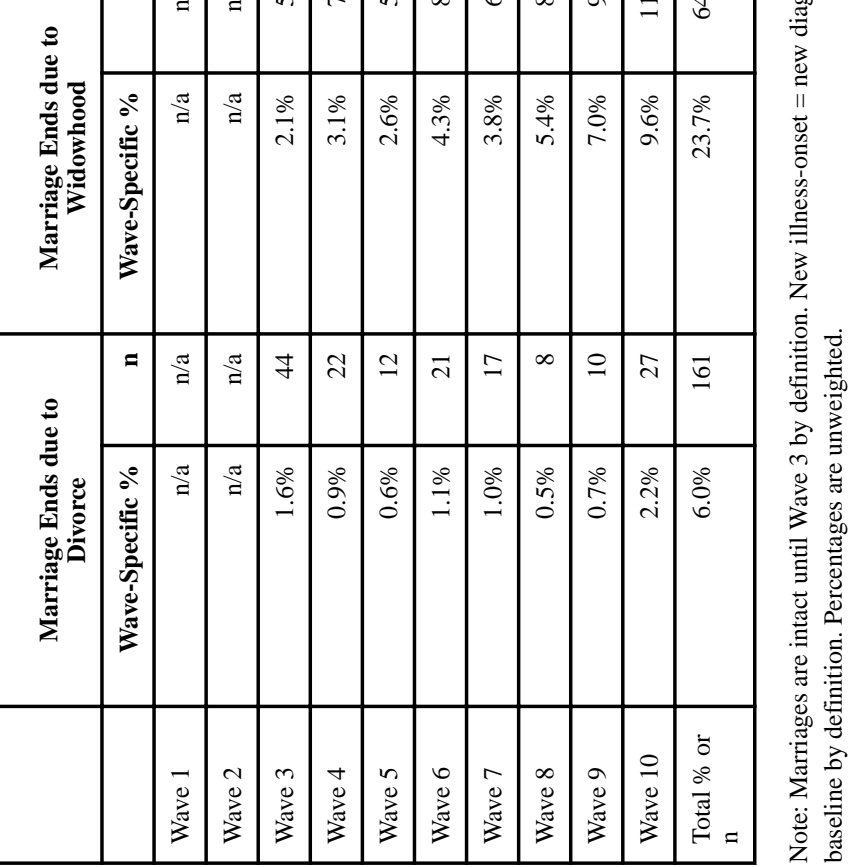

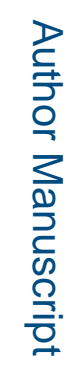

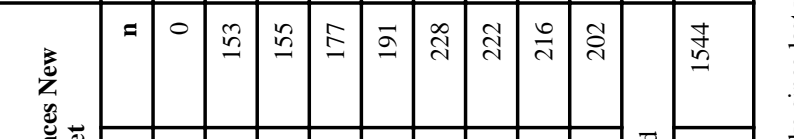

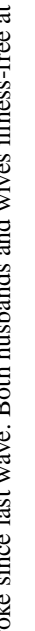




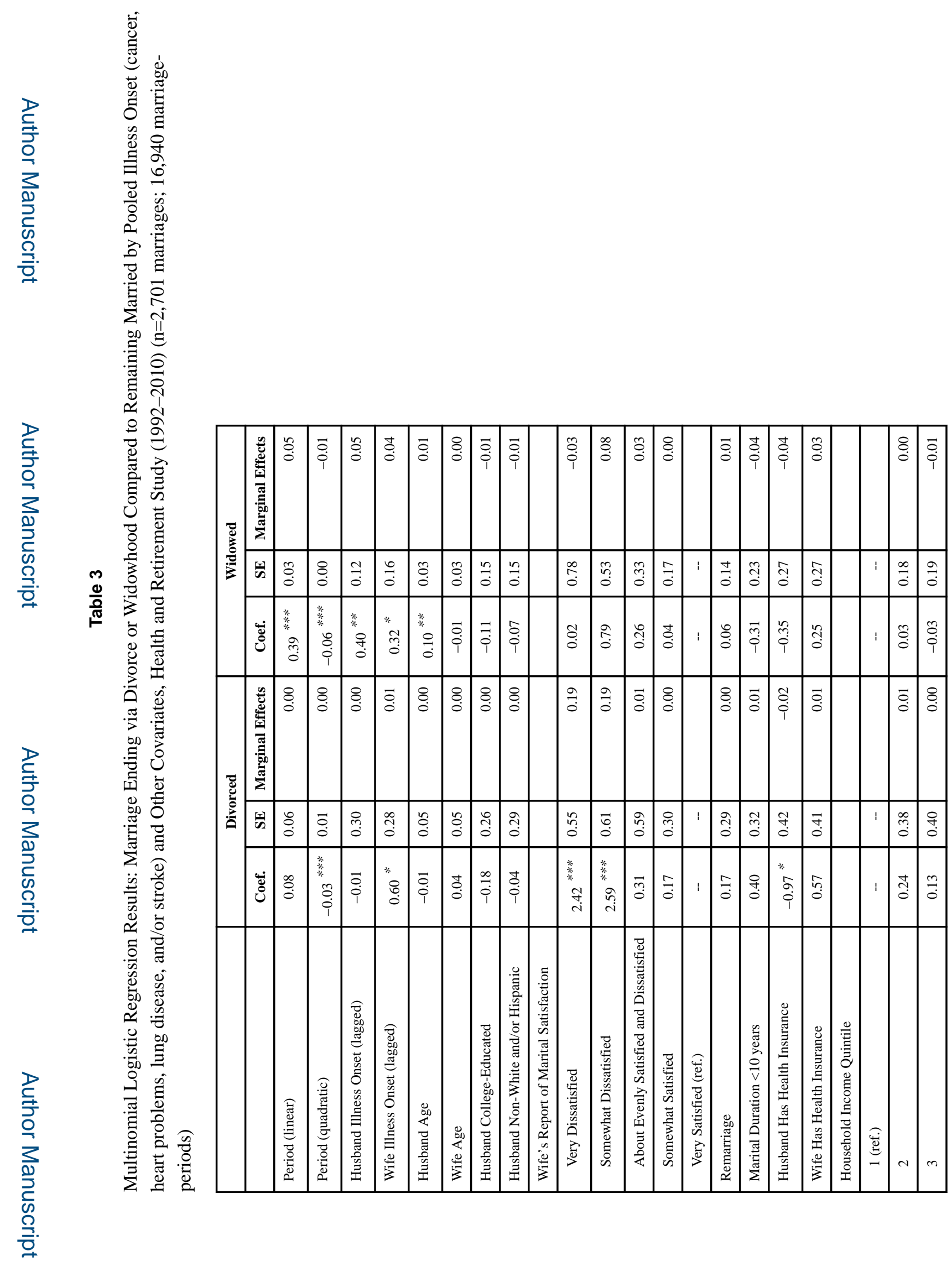

J Health Soc Behav. Author manuscript; available in PMC 2016 September 01. 


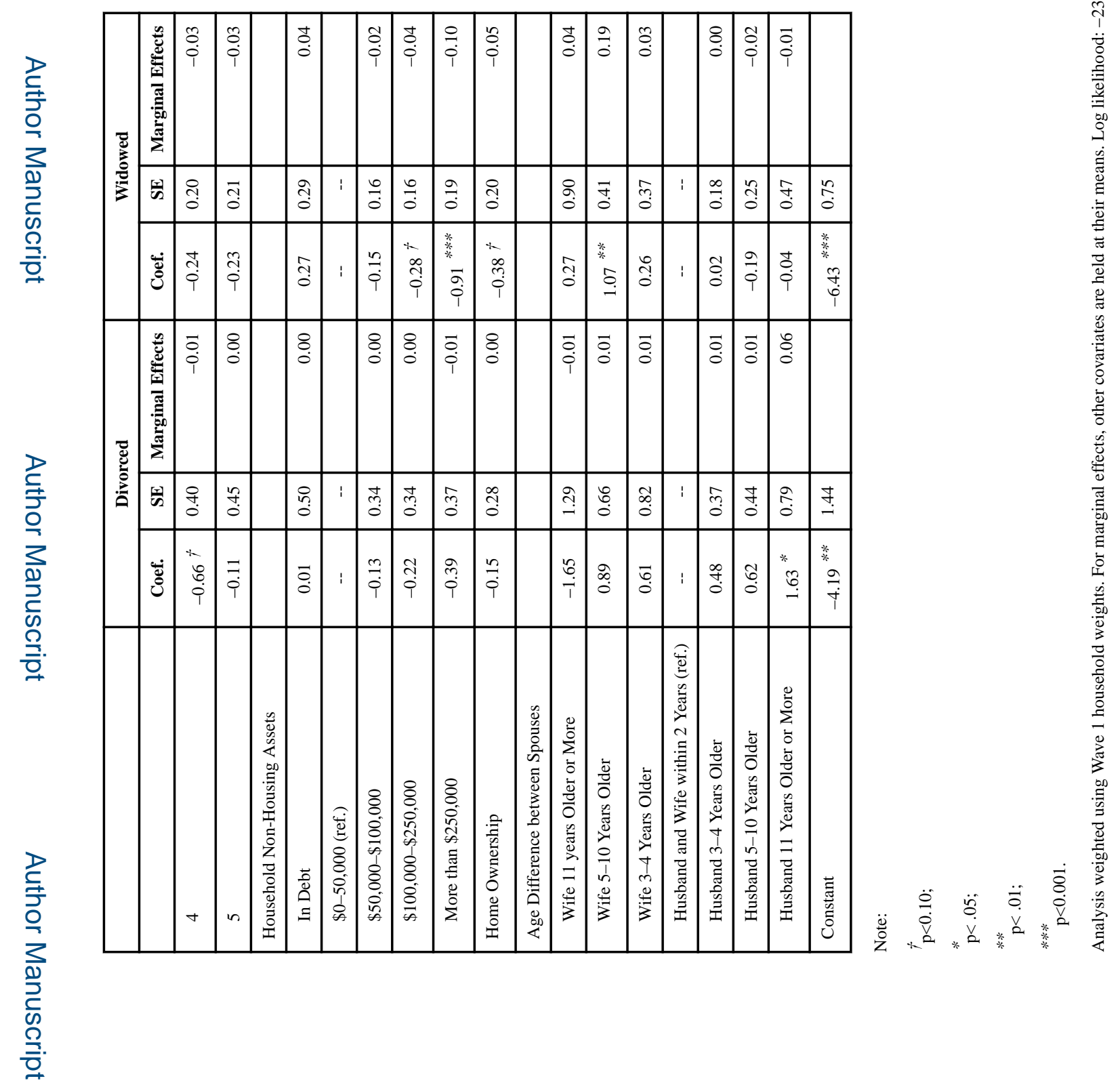

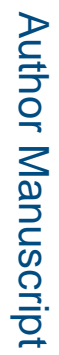




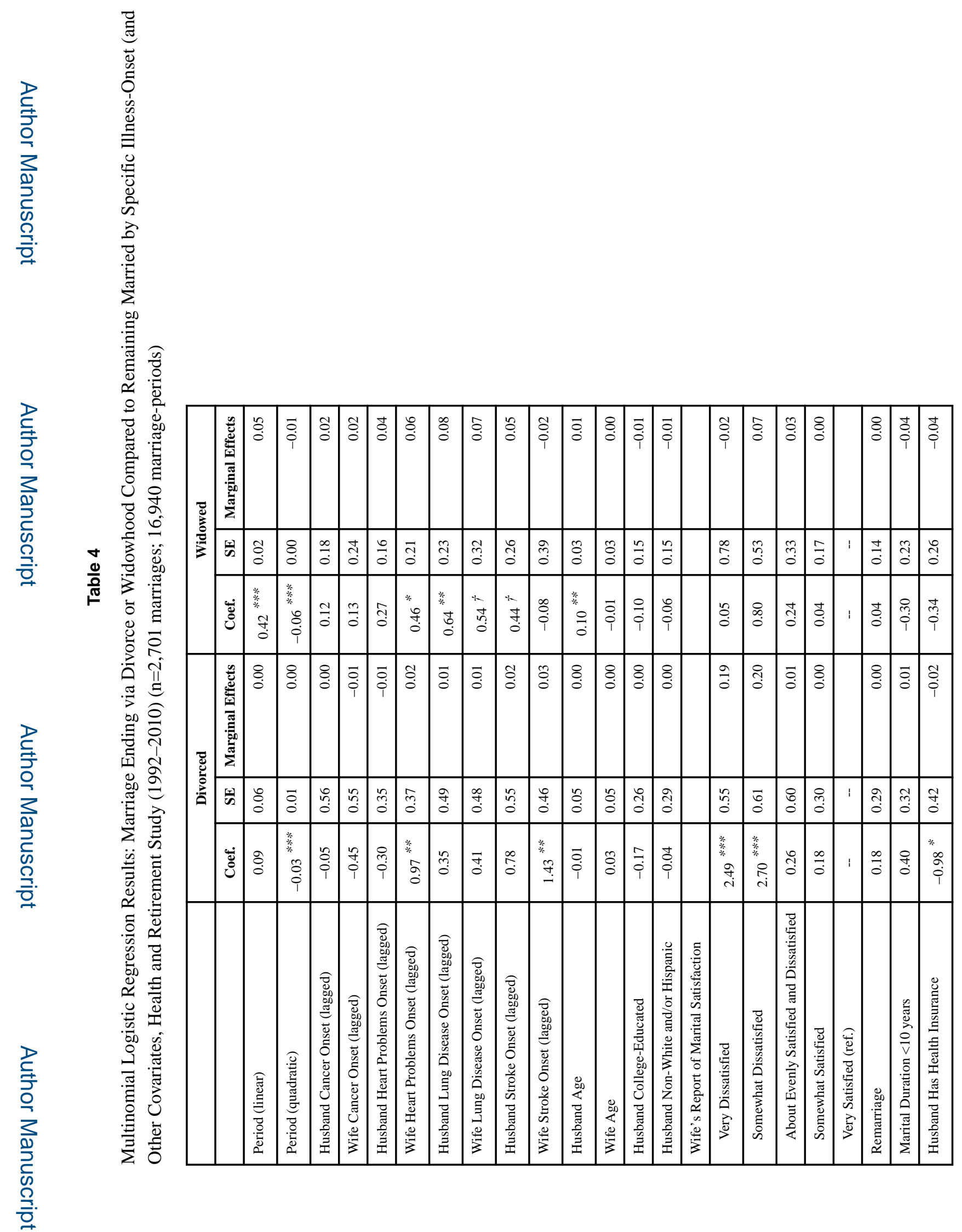

J Health Soc Behav. Author manuscript; available in PMC 2016 September 01. 


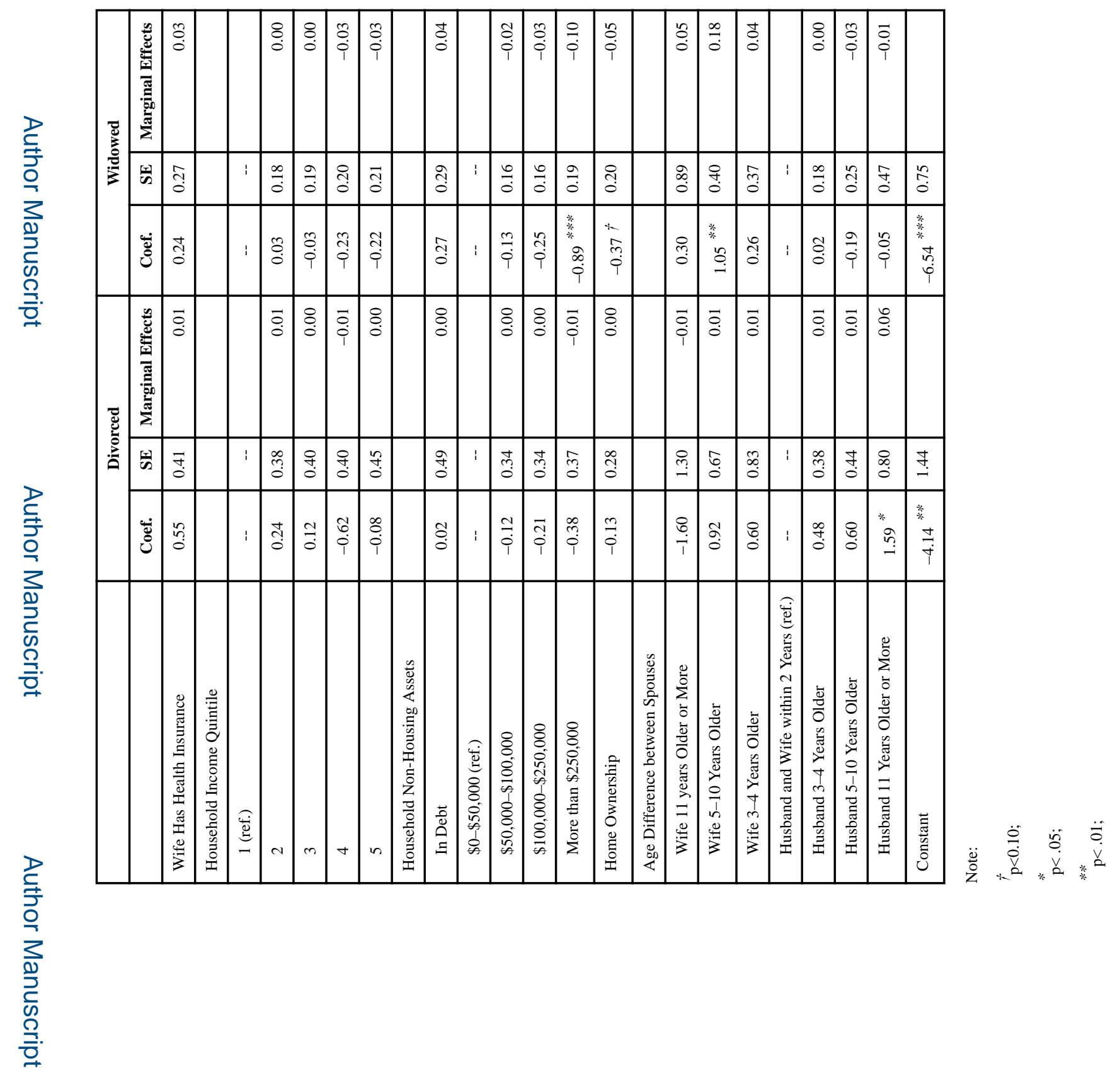

로을 


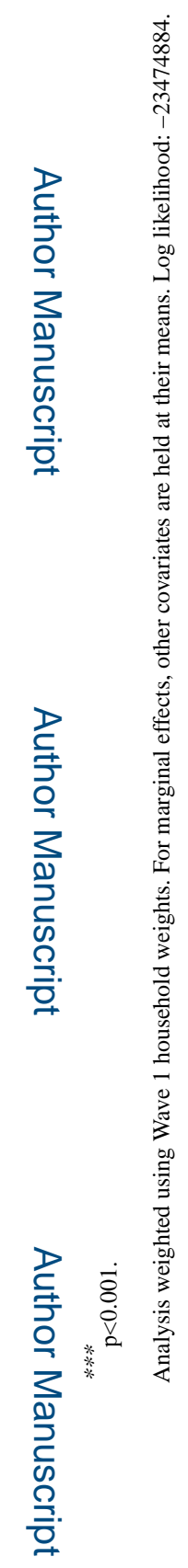

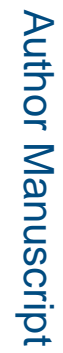

J Health Soc Behav. Author manuscript; available in PMC 2016 September 01. 